\title{
Multi-temporal dataset of stand and canopy structural data in temperate and Mediterranean coppice forests
}

\author{
Francesco Chianucci ${ }^{1}$ (D) $\cdot$ Carlotta Ferrara $^{1} \cdot$ Giada Bertini $^{1}$ - Gianfranco Fabbio ${ }^{1} \cdot$ Clara Tattoni $^{2}$ • Duccio Rocchini ${ }^{2,3,4}$. \\ Piermaria Corona ${ }^{1} \cdot$ Andrea Cutini $^{1}$
}

Received: 6 July 2018 / Accepted: 9 July 2019 / Published online: 1 August 2019

(C) INRA and Springer-Verlag France SAS, part of Springer Nature 2019

\begin{abstract}
- Key message We provided long-term stand and canopy structural data from permanent monitoring plots representative of some most diffuse temperate and Mediterranean forests, under different coppice management regimes. Periodic inventories were performed in the surveyed plots since the 1970s. Annual litterfall production and its partitioning (leaf, woody, reproductive parts) and optical canopy measurements using the LAI-2000 Plant Canopy Analyzer were performed every year in fully equipped plots since the 1990s. These data can be used for evaluating the influence of coppice management in the stand and canopy structure, the parametrization of radiative transfer models that require accurate ground truth data, and the calibration of high to medium resolution remotely sensed data. Dataset access is at https://doi.org/10.17632/z8zm3ytkcx.2. Associated metadata is available at https://agroenvgeo.data.inra.fr/geonetwork/srv/eng/catalog.search\#/metadata/2bd2d77f-3cf8-43da-b1b59f8196dc017f.
\end{abstract}

Keywords Coppice management $\cdot$ Canopy gap fraction $\cdot$ Leaf area index $\cdot$ Conversion $\cdot$ Litterfall

\section{Background}

Coppices are a significant part of Europe's semi-natural forests, characterizing forest landscapes of the five EU Mediterranean countries over about 8.5 million hectares

Handling Editor: Marianne Peiffer

Contribution of the co-authors All authors equally contributed to the work.

Francesco Chianucci

fchianucci@gmail.com; francesco.chianucci@crea.gov.it

Carlotta Ferrara

carlotta.ferrara@crea.gov.it

Giada Bertini

giada.bertini@crea.gov.it

Gianfranco Fabbio

gianfranco.fabbio@crea.gov.it

Clara Tattoni

clara.tattoni@gmail.com

Duccio Rocchini

duccio.rocchini@unitn.it
(Forest Europe 2015). Coppices were usually used as a source of firewood until the second half of the nineteenth century (Fabbio 2016). Economic and social changes occurred in the last decades have supported both coppice abandonment and their conversion into high forest, a situation common to many

Piermaria Corona

piermaria.corona@crea.gov.it

Andrea Cutini

andrea.cutini@crea.gov.it

1 CREA-FL, Research Centre for Forestry and Wood, viale Santa Margherita 80, 52100 Arezzo, Italy

2 Fondazione Edmund Mach, via Edmund Mach 1, San Michele all'Adige, 38010 Trento, Italy

3 University of Trento, Department of Cellular, Computational and Integrative Biology (CIBIO), Via Sommarive, 9, 38123 Povo, TN, Italy

4 Department of Applied Geoinformatics and Spatial Planning, Faculty of Environmental Sciences, Czech University of Life Sciences Prague, Kamýcka129, Praha - Suchdol 16500, Czech Republic 
European countries (Cañellas et al. 2004; Cutini et al. 2015; Chianucci et al. 2016b). Given the long time needed for achieving conversion, long-term data are required to define appropriate management strategies for these forests. Accurate in situ quantification of both stand and canopy structural attributes is also required for the parameterization of radiative transfer models (Kuusk et al. 2014) and calibration of remotely sensed information. However, in situ datasets are mainly available in boreal forests (e.g., Kuusk et al. 2009; Widlowski et al. 2013) and austral forests (e.g., Woodgate et al. 2015), while comparable datasets in temperate and Mediterranean forests are scarce.

Here, we provide long-term stand and canopy structural data in forest stands representative of some most diffuse temperate and Mediterranean forest types under different coppice management regimes.

\section{Methods}

\subsection{Study sites}

The dataset is a part of a wider project (LIFE 14 ENV/IT/ 000514 "FutureForCoppiceS"; www.futureforcoppices.eu) aimed to demonstrate the effect of different management options on sustainable forest management (SFM) criteria and indicators $(\mathrm{C} \& \mathrm{I})$ in coppice forests. In the project, different stands were surveyed in seven forest districts located in two Italian regions (Sardinia and Tuscany; Figure 1) belonging to long-term silvicultural trials established since the seventies of 1900 to monitoring the evolution of coppice stands under different management regimes. The plots were representative of three European forest types (EFT; Barbati et al. 2014): thermophilus deciduous forests dominated by Turkey oak (Quercus cerris L.) (EFT 8.2), mountainous beech (Fagus sylvatica L.) forests (7.3), evergreen broadleaved forests dominated by Holm oak (Quercus ilex L.) (9.1).

We included thirty-two project plots in the current database; two additional Turkey oak stands and one chestnut (Castanea sativa Mill.) stand (EFT 8.7) was also included from an independent field campaign. Periodic forest inventories were performed in these plots to survey dendrometric stand variables (tree density, basal area, mean diameter, mean height; Amorini et al. 1998a, b; Cutini 2002; Cutini et al. 1998; Chianucci and Cutini 2013). Litterfall production, its partitioning in leaf, woody and reproductive components, and optical canopy measurements using the LAI-2000 Plant Canopy Analyzer (LI-COR Inc. Lincoln, NE, USA) were performed every year in most of the plots since the nineties of 1900 (Cutini 2002). We classified as "fully equipped" the plots where all the dendrometric and canopy (litterfall, LAI-
2000) measurements have been performed. Table 1 lists the main characteristics of the selected plots.

\subsection{Structural data}

All standing trees (individuals with a stem diameter at $1.30 \mathrm{~m} \geq 3$ $\mathrm{cm}$ ) were surveyed, the species identified, and the diameter at breast height (dbh) measured. Mean dbh and basal area per hectare were then calculated from the measured diameters. When available, a sample of 30 trees was selected across the diameter range at each inventory. Dbh and height of the sampled trees were measured to calculate the height-diameter allometry. Mean height was then calculated as the height of mean diameter tree.

\subsection{Litterfall data}

When available, litterfall was collected from 9 to 15 litter-traps, each $0.5 \times 0.5 \mathrm{~m}$ in size, being systematically distributed along a grid, at $1 \mathrm{~m}$ above the ground level, with traps spaced 7 to 20 $\mathrm{m}$ apart, based on stand homogeneity and structure. Litter was periodically collected in fall-winter (usually between October and March, with the last collection completed soon after last litterfall). Litter was then sorted into its main components (leaf, woody, seed, husks, flowers), and then dried for $24 \mathrm{~h}$ to a constant weight in a forced-air stove at $85^{\circ} \mathrm{C} \pm 2^{\circ}$. Leaf litter was also separated for each species. Litter dry mass and its partitioning were then calculated $\left(\mathrm{Mg} \mathrm{ha}^{-1}\right)$ from total litter amount collected in fall-winter. We considered the reference year of sampling for litterfall as the sum of the litter collected in October-December of the current year and the litter collected in the January-March of the subsequent year. During this period, the sampled deciduous trees are in nonvegetative stage, and therefore, the litterfall collected refers to the previous vegetation period.

\subsection{Optical canopy data}

When available, optical canopy measurements were performed every year in each plot usually in summer (JunAug), just after dawn or close to sunset and under uniform sky conditions using the LAI-2000 Plant Canopy Analyzer. The optics of LAI-2000 consists of a fisheye lens $\left(148^{\circ}\right.$ field of view) divided into five concentric rings (with central zenith angle of $7^{\circ}, 23^{\circ}, 38^{\circ}, 53^{\circ}$, and $68^{\circ}$, respectively). Each ring simultaneously integrates incoming radiation in the 320-490 $\mathrm{nm}$ wavelength range (blue light) over the complete range of azimuth angle. Five view caps are provided with the instrument to reduce the azimuthal view of the optical sensor: $270^{\circ}$, $180^{\circ}, 90^{\circ}, 45^{\circ}$, and $10^{\circ}$.

One above-canopy reference measurement for each plot was recorded in clearings near each study area. The fisheye lens of the instrument was covered by a $90^{\circ}$ view 


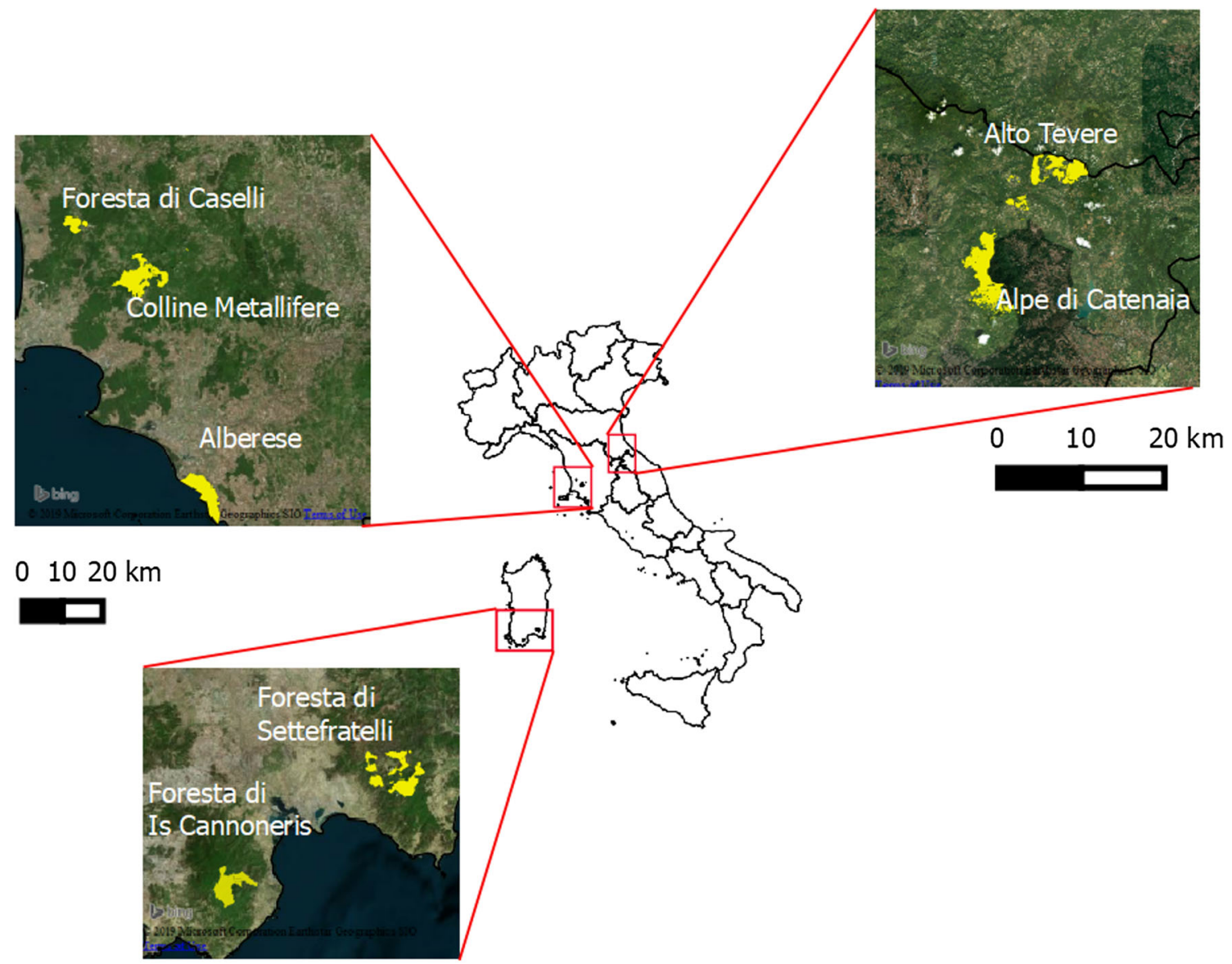

\section{$01020 \mathrm{~km}$}

Fig. 1 Forest districts considered in the LIFE FutureForCoppiceS project

cap to avoid the influence of surrounding trees on the reference measurements. Nine to 15 below-canopy measurements were recorded within each plot at the same grid points used for photography, using the same $90^{\circ}$ view cap. Gap fraction was estimated as the fraction of below- to above-canopy readings. Optical variables were then inferred from gap fraction using the FV2200 software version 1.2 (LI-COR Inc. Lincoln, NE, USA), which allowed to estimate effective leaf area index and leaf area index corrected for apparent clumping (see Ryu et al. 2010 for details) using Miller's (1967) theorem. Alternative leaf area index methods calculated from the software include Lang's interpolating method (1987), the Ellipsoidal method (Campbell 1986), and the constrained least square method (Perry et al. 1988).

\section{Access to data and metadata description}

The dataset can be downloaded using the following reference and doi: Chianucci F, Ferrara C, Bertini G, Fabbio
G, Tattoni C, Rocchini D, Corona P, Cutini A (2018). Multi-temporal dataset of stand and canopy structural data in temperate and Mediterranean coppice forests. Mendeley Data, v2, [dataset], https://doi.org/10.17632/ z8zm3ytkcx.2 under the Creative Commons Attribution-NonCommercial 4.0 License. The repository URL contains a descriptive table ("Tbl_description") with information about the plots and four data tables ("Tbl Inventory," "Tbl_LAI-2000," "Tbl_Leaf_Seed_Litter," and "Tbl_Woody_Litter"). Illustrative images of the plots are also available as a compressed file ("Images.rar"). Associated metadata are available at https://agroenvgeo. data.inra.fr/geonetwork/srv/eng/catalog.search\#/metadata/ 2bd2d77f-3cf8-43da-b1b5-9f8196dc017f. The metadata include (i) documentation on data provision and discovery, (ii) information on the data protocol in use, origin, and context, and (iii) technical documentation describing all the provided variables provided along with the data structure. All the data are provided without georeferenced information; georeferenced data are however available from the authors upon request. 
Table 1 General description of the database plots. Asterisks indicate the plots not belonging to the LIFE FutureForCoppiceS Project

\begin{tabular}{|c|c|c|c|c|c|c|}
\hline$N$ & ID_plot & Region & Forest district & $\begin{array}{l}\text { European forest } \\
\text { type (EFT) }\end{array}$ & Management option & $\begin{array}{l}\text { Fully- } \\
\text { equipped }\end{array}$ \\
\hline 1 & qiA2isc & Sardinia & Foresta di Is Cannoneris & 9.1 & $\begin{array}{l}\text { Active conversion through } \\
\text { periodic thinning }\end{array}$ & No \\
\hline 2 & qiA3isc & Sardinia & Foresta di Is Cannoneris & 9.1 & $\begin{array}{l}\text { Active conversion } \\
\text { through periodic thinning }\end{array}$ & No \\
\hline 3 & qiAisc & Sardinia & Foresta di Is Cannoneris & 9.1 & $\begin{array}{l}\text { Active conversion } \\
\text { through periodic thinning }\end{array}$ & Yes \\
\hline 4 & qiB2isc & Sardinia & Foresta di Is Cannoneris & 9.1 & $\begin{array}{l}\text { Active conversion } \\
\text { through periodic thinning }\end{array}$ & No \\
\hline 5 & qiB3isc & Sardinia & Foresta di Is Cannoneris & 9.1 & $\begin{array}{l}\text { Active conversion } \\
\text { through periodic thinning }\end{array}$ & No \\
\hline 6 & qiBisc & Sardinia & Foresta di Is Cannoneris & 9.1 & $\begin{array}{l}\text { Active conversion through } \\
\text { periodic thinning }\end{array}$ & Yes \\
\hline 7 & qiT2isc & Sardinia & Foresta di Is Cannoneris & 9.1 & $\begin{array}{l}\text { Natural evolution } \\
\quad \text { (unthinned control) }\end{array}$ & No \\
\hline 8 & qiT3isc & Sardinia & Foresta di Is Cannoneris & 9.1 & $\begin{array}{l}\text { Natural evolution } \\
\quad \text { (unthinned control) }\end{array}$ & No \\
\hline 9 & qiTisc & Sardinia & Foresta di Is Cannoneris & 9.1 & $\begin{array}{l}\text { Natural evolution } \\
\quad \text { (unthinned control) }\end{array}$ & Yes \\
\hline 10 & qiAlacq & Sardinia & Foresta di Settefratelli & 9.1 & $\begin{array}{l}\text { Active conversion through } \\
\text { periodic thinning }\end{array}$ & Yes \\
\hline 11 & qiA2acq & Sardinia & Foresta di Settefratelli & 9.1 & $\begin{array}{l}\text { Active conversion through } \\
\text { periodic thinning }\end{array}$ & Yes \\
\hline 12 & csAVVcate* & Tuscany & Alpe di Catenaia & 8.7 & $\begin{array}{l}\text { Active conversion through } \\
\text { periodic thinning }\end{array}$ & Yes \\
\hline 13 & fsCEDcolt1 & Tuscany & Alpe di Catenaia & 7.3 & Traditional coppice & No \\
\hline 14 & fsCEDcolt2 & Tuscany & Alpe di Catenaia & 7.3 & Traditional coppice & No \\
\hline 15 & fsCEDgeom1 & Tuscany & Alpe di Catenaia & 7.3 & Traditional coppice & No \\
\hline 16 & fsCEDgeom2 & Tuscany & Alpe di Catenaia & 7.3 & Traditional coppice & No \\
\hline 17 & fsCONTRcate & Tuscany & Alpe di Catenaia & 7.3 & $\begin{array}{l}\text { Active conversion through } \\
\text { periodic thinning }\end{array}$ & Yes \\
\hline 18 & fsDIR3cate & Tuscany & Alpe di Catenaia & 7.3 & $\begin{array}{l}\text { Active conversion through } \\
\text { periodic thinning }\end{array}$ & No \\
\hline 19 & fsDIR4cate & Tuscany & Alpe di Catenaia & 7.3 & $\begin{array}{l}\text { Active conversion through } \\
\text { periodic thinning }\end{array}$ & No \\
\hline 20 & fsDIR5cate & Tuscany & Alpe di Catenaia & 7.3 & $\begin{array}{l}\text { Active conversion through } \\
\text { periodic thinning }\end{array}$ & No \\
\hline 21 & fsDIRcate & Tuscany & Alpe di Catenaia & 7.3 & $\begin{array}{l}\text { Active conversion through } \\
\text { periodic thinning }\end{array}$ & Yes \\
\hline 22 & fsTESTcate & Tuscany & Alpe di Catenaia & 7.3 & $\begin{array}{l}\text { Natural evolution } \\
\quad \text { (unthinned control) }\end{array}$ & Yes \\
\hline 23 & fsTScate & Tuscany & Alpe di Catenaia & 7.3 & Anticipated seed cutting & Yes \\
\hline 24 & qcAVVcate* & Tuscany & Alpe di Catenaia & 8.2 & $\begin{array}{l}\text { Active conversion through } \\
\text { periodic thinning }\end{array}$ & Yes \\
\hline 25 & qcDvals & Tuscany & Alto Tevere & $\mathrm{T} 8.2$ & $\begin{array}{l}\text { Active conversion through } \\
\text { periodic thinning }\end{array}$ & Yes \\
\hline 26 & qcTvals & Tuscany & Alto Tevere & 8.2 & $\begin{array}{l}\text { Natural evolution } \\
\quad \text { (unthinned control) }\end{array}$ & Yes \\
\hline 27 & qc112mass & Tuscany & Colline Metallifere & 8.2 & $\begin{array}{l}\text { Natural evolution } \\
\quad \text { (unthinned control) }\end{array}$ & Yes \\
\hline 28 & qc1324mass & Tuscany & Colline Metallifere & 8.2 & Traditional coppice & Yes \\
\hline 29 & qc2536mass & Tuscany & Colline Metallifere & 8.2 & $\begin{array}{l}\text { Active conversion through } \\
\text { periodic thinning }\end{array}$ & Yes \\
\hline 30 & qc3748mass* & Tuscany & Colline Metallifere & 8.2 & $\begin{array}{l}\text { Active conversion through } \\
\text { periodic thinning }\end{array}$ & Yes \\
\hline 31 & qcCEDmass & Tuscany & Colline Metallifere & 8.2 & Traditional coppice & No \\
\hline 32 & qcDlcase & Tuscany & Foresta di Caselli & 8.2 & $\begin{array}{l}\text { Active conversion through } \\
\text { periodic thinning }\end{array}$ & Yes \\
\hline 33 & qcD3case & Tuscany & Foresta di Caselli & 8.2 & $\begin{array}{l}\text { Active conversion through } \\
\text { periodic thinning }\end{array}$ & Yes \\
\hline 34 & qcT1case & Tuscany & Foresta di Caselli & 8.2 & Natural evolution (unthinned control) & Yes \\
\hline 35 & qcT3case & Tuscany & Foresta di Caselli & 8.2 & Natural evolution (unthinned control) & Yes \\
\hline
\end{tabular}




\section{Technical validation}

The dataset includes four data tables ("Tbl_Inventory," "Tbl_LAI-2000," "Tbl Leaf Seed Litter," and "Tbl_Woody Litter") comprising respectively 136, 1399, 951, and 378 records, for a total of 2864 measurements (records) associated with the 35 plots. Field inventory and litterfall collection have been conducted by four expert foresters. For leaf litter, identification of species has been performed in the laboratory by one expert botanist. The adopted nomenclature of leaf litter was set according to the UNECE/ ICP species code (available at: http://icp-forests.net/page/ expert-panel-on-biodiversity). Optical measurements using the LAI-2000 were conducted by one expert in optical canopy analyses.

Data cleansing have been performed to check for data quality. Data inconsistency originating by errors in user entry (e.g., typographical errors), data type storage, and field measurements have been checked by two independent expert users. Example of data quality analysis included data type constraints (e.g., values in a field must meet the desired data type), range constraints (minimum and maximum values allowed for numerical variables), and numeric constraints (e.g., tree height must not decrease through time).

\section{Reuse potential and limits}

The dataset allows characterizing the structure of forest stands which are representative of most diffuse European forest types, along with its variation over time. Forest inventory yielded traditional stand variables, while periodic repetition allows the examination of changes in stand structure due to mortality, growth, regeneration, and management.

Litterfall is a key descriptor of stand vitality, soil nutrient status, and forest ecosystem productivity, while its temporal distribution provides information about the influence of environmental factors and natural/ anthropogenic disturbances on ecosystem dynamics. In addition, while most litterfall datasets are mainly limited to leaf litter, the current dataset provides also data on seed production, which can be used to either evaluate the influence of climate on mast seeding (Vacchiano et al. 2017) and assess the influence of masting on pulsed-resource consumers like wild boar (Bisi et al. 2018).

Leaf area index and other optical attributes are useful for multiple purposes, including (i) evaluating the influence of climate and management on forest canopy structure; (ii) monitoring stand vitality and productivity; (iii) parametrizing ecological and processed-based canopy photosynthesis models. New algorithms can be tested using the gap fraction data (columns "AVGTRANS") to improve estimation of canopy attributes like leaf area index (e.g., Gonsamo et al. 2018) and clumping index (e.g., Chianucci et al. 2019).

Other applications from the available data include the parameterization of radiative transfer models that require accurate ground truth data (Kuusk et al. 2014; Nilson 1999), as well as the calibration of remotely sensed information. The plot size is suitable for comparison with high to medium resolution aerial and satellite products and unmanned aerial vehicles (Chianucci et al. 2016a).

Although the data have been limited to relatively few plots, the temporal resolution allows a long-term assessment of the management influence within each stand, which is representative of the most widespread temperate and Mediterranean forest types. In addition, the selected variables and used experimental designs were in accordance with those of other studies specifically addressing forest dynamics (e.g., Genet et al. 2010; Meier and Leuschner 2008) and long-term forest monitoring programs such as UNECE $\backslash$ ICP (icp-forests.net), allowing large-scale comparison with other datasets and studies.

Finally, we foresee to periodically replicate measurements, so we plan to include new measurements in the dataset once they will be made available in future field campaigns.

Acknowledgments We thank the anonymous Reviewer and the handling Editor Marianne Peiffer for the constructive comments, which improved the original version of the manuscript. We are grateful for all technicians of CREA, who contributed to field data collection, with particular reference to Maurizio Piovosi, Luca Marchino, Tessa Giannini, Umberto di Salvatore, Leonardo Tonveronachi, Valter Cresti, Eligio Bucchioni, Umberto Cerofolini, and Luigi Mencacci.

Funding The dataset has partly been compiled within the LIFE 14 ENV/ IT/000514 "Shaping future forestry for sustainable coppices in southern Europe: the legacy of past management trials"-FutureForCoppiceS (www.futureforcoppices.eu).

Data availability statement The data are available under the Creative Commons Attribution-Non Commercial 4.0.

\section{Compliance with ethical standards}

Conflict of interest The authors declare that they have no conflict of interest.

\section{References}

Amorini E, Bruschini S, Cutini A, Di Lorenzo MG, Fabbio G (1998a) Treatment of Turkey oak (Quercus cerris L.) coppices. Structure, biomass and silvicultural options. Ann Ist Sper Selv 27(1996): 121-129

Amorini E, Bruschini S, Cutini A, Fabbio G, Manetti MC (1998b) Silvicultural treatment of holm oak (Quercus ilex L.) coppices in 
Southern Sardinia: thinning and related effects on stand structure and canopy cover. Ann Ist Sper Selv 27(1996):167-176

Barbati A, Marchetti M, Chirici G, Corona P (2014) European forest types and forest Europe SFM indicators: tools for monitoring progress on forest biodiversity conservation. For Ecol Manag 321:145157

Bisi F, Chirichella R, Chianucci F, Von Hardenberg J, Cutini A, Martinoli A, Apollonio M (2018) Climate, tree masting and spatial behaviour in wild boar (Sus scrofa L.): insight from a long-term study. Ann For Sci 75(2):46

Campbell GS (1986) Extinction coefficients for radiation in plant canopies calculated using an ellipsoidal inclination angle distribution. Agric For Meteorol 36:317-321

Cañellas I, Del Rìo M, Roig S, Montero G (2004) Growth response to thinning in Quercus pyrenaica Willd. coppice stands in Spanish central mountain. Annals of Forest. Sciences 61:243-250

Chianucci F, Cutini A (2013) Estimation of canopy properties in deciduous forests with digital hemispherical and cover photography. Agric For Meteorol 160:130-139

Chianucci F, Disperati L, Guzzi D, Bianchini D, Nardino V, Lastri C, Rindinella A, Corona P (2016a) Estimation of canopy attributes in beech forests using true colour digital images from a small fixedwing UAV. Int J Appl Earth Obs Geoinf 47:60-68

Chianucci F, Salvati L, Giannini T, Chiavetta U, Corona P, Cutini A (2016b) Long-term response to thinning in a beech (Fagus sylvatica L.) coppice stand under conversion to high forest in Central Italy. Silva Fennica 50

Chianucci F, Ferrara C, Bertini G, Fabbio G, Tattoni C, Rocchini D, Corona P, Cutini A (2018) Multi-temporal dataset of stand and canopy structural data in temperate and Mediterranean coppice forests. Mendeley Data. V2. [Dataset]. https://doi.org/10.17632/ z8zm3ytkcx.2

Chianucci F, Zou J, Leng P, Zhuang Y, Ferrara C (2019) A new method to estimate clumping index integrating gap fraction averaging with the analysis of gap size distribution. Can J For Res (early view. https:// doi.org/10.1139/cjfr-2018-0213

Cutini A (2002) Litterfall and leaf area index in the CONECOFOR Permanent Monitoring Plots. J Limnol 61:62-68

Cutini A, Matteucci G, Scarascia Mugnozza G (1998) Estimation of leaf area index with the Li-Cor LAI 2000 in deciduous forests. For Ecol Manag 105:55-65

Cutini A, Chianucci F, Giannini T, Manetti MC, Salvati L (2015) Is anticipated seed cutting an effective option to accelerate transition to high forest in European beech (Fagus sylvatica L.) coppice stands? Ann For Sci 72(5):631-640

Europe F (2015) State of Europe's forests. Martin M, Forest Europe. Liaison Unit Madrid, Europe's Status \& Trends in Sustainable Forest Management in Europe. Project coordinator, p 2015
Fabbio G (2016) Coppice forests, or the changeable aspect of things, a review. Ann Silvicult Res 40(2):108-132

Genet H, Bréda N, Dufrêne E (2010) Age-related variation in carbon allocation at tree and stand scales in beech (Fagus sylvatica L.) and sessile oak (Quercus petraea (Matt.) Liebl.) using a chronosequence approach. Tree Physiol 30:177-192

Gonsamo A, Walter JM, Chen JM, Pellikka P, Schleppi P (2018) A robust leaf area index algorithm accounting for the expected errors in gap fraction observations. Agric For Meteorol 248:197-204

Kuusk A, Kuusk J, Lang M (2009) A dataset for the validation of reflectance models. Remote Sens Environ 113(5):889-892

Kuusk A, Kuusk J, Lang M (2014) Modeling directional forest reflectance with the hybrid type forest reflectance model FRT. Remote Sens Environ 149:196-204

Lang ARG (1987) Simplified estimate of leaf area index from transmittance of the sun's beam. Agric And For Meteor 41:179-186

Meier IC, Leuschner C (2008) Leaf size and leaf area index in Fagus sylvatica forests: competing effects of precipitation, temperature and nitrogen availability. Ecosystems 11:655-669

Miller JB (1967) A formula for average foliage density. Aust J Bot 15: $141-144$

Nilson T (1999) Inversion of gap frequency data in forest stands. Agric For Meteorol 98:437-448

Perry SG, Fraser AB, Thomson DW, Norman JM (1988) Indirect sensing of plant canopy structure with simple radiation measurements. Agric And For Meteor 42:255-278

Ryu Y, Nilson T, Kobayashi H, Sonnentag O, Law BE, Baldocchi DD (2010) On the correct estimation of effective leaf area index: does it reveal information on clumping effects? Agric For Meteorol 150: 463-472

Vacchiano G, Hacket-Pain A, Turco M, Motta R, Maringer J, Conedera M, Ascoli D (2017) Spatial patterns and broad-scale weather cues of beech mast seeding in Europe. New Phytol 215(2):595-608

Widlowski JL, Pinty B, Lopatka M, Atzberge C, Buzica D, Chelle M, Disney M, Gastellu-Etchegorry JP, Gerboles M, Gobron N, Grau E (2013) The fourth radiation transfer model intercomparison (RAMIIV): proficiency testing of canopy reflectance models with ISO13528. J Geophys Res Atmos 118(13):6869-6890

Woodgate W, Disney M, Armston JD, Jones SD, Suarez L, Hill MJ, Wilkes P, Soto-Berelov M, Haywood A, Mellor A (2015) An improved theoretical model of canopy gap probability for leaf area index estimation in woody ecosystems. For Ecol Manag 358:303320

Publisher's note Springer Nature remains neutral with regard to jurisdictional claims in published maps and institutional affiliations. 